\title{
The impact of agricultural soil erosion on biogeochemical
}

\section{cycling}

John Quinton, Lancaster University, Gerard Govers, KU Leuven and Kristof Van Oost

UC Louvain, Richard Bardgett, Lancaster University

\section{Introductory paragraph}

It is widely recognized that soils play a key role in controlling the storage, transformation and flux of nutrients and carbon (C) through the lithosphere and biosphere. Despite this, our understanding of the role that soils play in biogeochemical cycles does not conventionally take into account erosion, lateral movement and soil mixing. Here, we synthesize data on the global fluxes of soil C, nitrogen $(\mathrm{N})$ and phosphorus $(\mathrm{P})$ moving over agricultural landscapes as a result of erosion processes. We demonstrate how the mobilization and deposition of soil can have significant impacts on carbon and nutrient cycling causing lateral fluxes of $\mathrm{N}$ and $\mathrm{P}$ similar in magnitude to those induced by fertilizer application and crop removal. The translocation and burial of $\mathrm{C}$ reduces decomposition and may lead to a potential C sink. Cycling of $\mathrm{C}, \mathrm{N}$ and $\mathrm{P}$ and phosphorus are strongly interrelated, and lateral fluxes of soil, $\mathrm{C}$ and associated nutrients have significant consequences for primary productivity, which in turn influences the replacement of lost C. Our analysis demonstrates why soils must be viewed as dynamic systems in time and space if we are to understand their role in major biogeochemical cycles. 


\section{Introduction}

Soils are the major terrestrial reservoir of organic carbon (C) and nutrients such as nitrogen (N) and phosphorus (P), and the potential impact of soil processes on the biogeochemical cycling of these elements remains one of the great uncertainties in our knowledge of global climate change ${ }^{1,2}$. Beginning with the pioneering work of Stallard ${ }^{3}$, scientists have become increasingly aware that lateral fluxes induced by soil erosion are of key importance in the global C cycle. Work on the relationship between erosion and nutrients has hitherto focused mainly on potential losses of nutrients due to erosion and the effect on primary productivity; potential effects of erosion on global nutrient cycling and their interrelationship with the carbon cycle have not yet been studied in detail. In this progress article we estimate the impact of soil erosion on the cycling of $\mathrm{C}, \mathrm{N}$ and P using global datasets and identify mechanisms through which erosion and $\mathrm{C}, \mathrm{N}$ and $\mathrm{P}$ cycling may interact.

\section{Mobilizing elements}

Several estimates of global soil and C erosion rates associated with agriculture have been made in recent years. From a critical analysis of these estimates we calculate the sediment by water erosion flux to be about $28 \mathrm{Pg} \mathrm{yr}^{-1}$, and that an additional approximately $5 \mathrm{Pg} \mathrm{yr}^{-1}$ and $2 \mathrm{Pg} \mathrm{yr}^{-1}$ of sediment are mobilized by tillage and wind erosion, respectively, leading to a total sediment flux of about 35

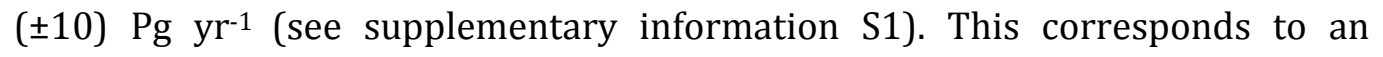
agricultural C erosion flux of $0.5( \pm 0.15) \mathrm{Pg} \mathrm{C} \mathrm{yr}^{-1}$ and an estimate of $0.08( \pm 0.02)$ Pg for C delivery to river systems by water erosion. 
To estimate the flux of $\mathrm{N}$ associated with erosion processes, we combine spatial estimates of soil erosion with global soil $\mathrm{N}$ data ${ }^{4}$ (see supplementary information S1). We estimate the amount of $\mathrm{N}$ moved by erosion to be of the order of 23-42 $\mathrm{Tg} \mathrm{N} \mathrm{yr}^{-1}$. Lateral fluxes of $\mathrm{N}$ due to erosion are of the same order of magnitude as

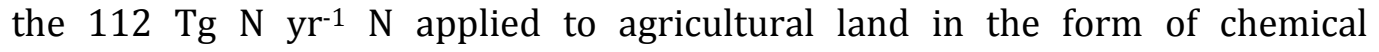
fertilizers ${ }^{5}$, the $75 \mathrm{Tg} \mathrm{yr}^{-1} \mathrm{~N}$ removed in harvested crops ${ }^{6}$ and the estimated riverine fluxes of particulate $\mathrm{N}$ of between 23 and $30 \mathrm{Tg} \mathrm{N} \mathrm{yr}^{-1}$ 7,8. We estimate soil erosion-driven terrestrial fluxes of organic and inorganic $\mathrm{P}$ to be $2.1-3.9 \mathrm{Tg}$

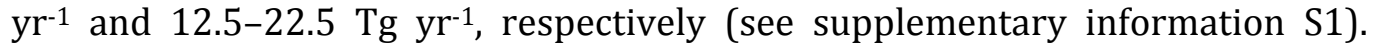
However, due to the limited availability of global soil $\mathrm{P}$ data these estimates are uncertain. Global mean P fluxes are considerably lower than the 40 Pg of global soil P stocks ${ }^{9}$, but of similar magnitude to crop uptake ${ }^{6}\left(14 \mathrm{Tg} \mathrm{yr}^{-1}\right)$ and fertilizer


global fluxes of $\mathrm{P}$ do exceed $\mathrm{P}$ additions (Figure 1), adding further downward pressures on soil fertility, and food production.

\section{Eroding the carbon cycle}

Soil erosion encompasses soil mobilization (detachment), transport and deposition phases. Understanding erosional effects on biogeochemical cycles requires consideration of all three components. When soil material is mobilized, soil structure is at least partially disrupted. Laboratory experiments indicate that a significant increase in the rate of soil organic C (SOC) mineralization is possible during or shortly after sediment mobilization, potentially leading to the loss of $>20 \%$ of the total SOC as $\mathrm{CO}_{2}, 10$. When considering the potential role of the transport phase, a distinction should be made between SOC deposited in a local 
depositional store after being transported over a relatively small distance $(<5 \mathrm{~m})$ by water or tillage with a short time span $(<1$ day), and the fate of SOC that is delivered to the river ecosystem. Field observations suggest the additional SOC mineralization that occurs during transport over land is relatively unimportant: erosion-deposition simulations based on ${ }^{137} \mathrm{Cs}$ inventories show that the $\mathrm{C}$ inventory found at depositional sites is inconsistent with significant mineralization during the transport phase ${ }^{11}$. Recent observations under field conditions suggest that SOC losses from soil that is re-deposited after a short transport phase are relatively low $(<2.5 \%$ of eroded SOC), and therefore not very significant for the global C budget ${ }^{12}$. On the other hand, SOC that is delivered to the river system may be to a large extent mineralized within the river system ${ }^{13}$.

Understanding erosional effects on biogeochemical cycling also requires consideration of longer-term effects. Recent work on the impact of soil erosion on the $\mathrm{C}$ cycle has implicated eroded sites in both increased emissions and sequestration of C. While soil structure disruption during erosion may immediately lead to $\mathrm{CO}_{2}$ emission, enhanced emissions over longer time spans are associated with a reduced capacity of eroded soils to support plant growth ${ }^{14}$ resulting in lower $\mathrm{C}$ inputs through plant and root matter ${ }^{15}$. Erosion will also lead to local mixing of C-depleted subsoil into the plough layer. This offers potential for $\mathrm{C}$ sequestration through so-called dynamic replacement ${ }^{16}$ as: (i) the mean $\mathrm{C}$ concentration in the soil will be reduced and will therefore be lower than the equilibrium $\mathrm{C}$ concentration; and (ii) as relatively fresh mineral surfaces will be exposed on which soil organic matter may be more easily bound. If erosion is controlled there is potential for additional $\mathrm{C}$ sequestration at eroded sites as SOM contents may increase. The promotion of $\mathrm{C}$ sequestration by erosion relies 
on a reduced rate of SOC decomposition because sediment is buried in depositional environments. Although the mechanisms which contribute to the reduction of decomposition at depth ${ }^{17}$ have only recently received attention ${ }^{18}$, the burial of pedogenic $C$ at sites of deposition has been shown repeatedly to stabilize soil $\mathrm{C}$ at timescales of several decades, leading to reduced atmospheric release of $\mathrm{C}^{11}$. In addition to this passive mechanism of SOC mineralization suppression, active sequestration can also take place in depositional environments with a higher net primary production than the source areas. For example, the influx of low $\mathrm{C}$ sediment into wetlands and lowland valley bottoms may stimulate net $\mathrm{C}$ sequestration by diluting the concentration of soil $\mathrm{C}^{3}$. Overall, the extent to which mobilization and deposition lead to an overall sink of atmospheric $\mathrm{CO}_{2}$ is critically dependent on how much of the depositional accumulation is replaced by newly produced plant-derived soil $\mathrm{C}$ at eroding $\operatorname{sites}^{16}$ (figure 2).

The removal of soil also brings the subsoil and parent material closer to the soil surface. For silicate-rich parent material there is increasing empirical and theoretical evidence for a link between erosion and rates of chemical weathering under steady state conditions ${ }^{19,20}$. Since the weathering of silicate minerals consumes $\mathrm{CO}_{2}$, it seems likely that there may also be a link between erosioninduced weathering and the consumption of $\mathrm{CO}_{2}$, although the flux is likely to be small,. In contrast, where parent materials are calcareous, accelerated weathering may result in $\mathrm{CO}_{2}$ release to the atmosphere. For example, in the Canadian prairies it has been estimated that that $10 \%$ of the carbonates acidified may be released as $\mathrm{CO}_{2}$, producing an estimated $\mathrm{C}$ loss of 0.12 to $1.2 \mathrm{Mg} \mathrm{ha}^{-1} \mathrm{yr}^{-1}$ 21. 


\section{Impact on nutrient cycles}

Work on the effects of erosion on $\mathrm{N}$ and $\mathrm{P}$ cycling has hitherto concentrated on the assessment of nutrient mobilization and delivery to aquatic ecosystems. Very little work has been carried out on how $\mathrm{N}$ and $\mathrm{P}$ cycling within terrestrial environments are affected by erosion. Here we propose a conceptualization of how the effects of erosion on $\mathrm{C}, \mathrm{N}$ and $\mathrm{P}$ cycling may be interrelated. Because large amounts of $\mathrm{N}$ and $\mathrm{P}$ are retained within the soil organic matter (SOM) fraction, enhanced mineralization of soil $\mathrm{C}$ due to soil mobilization ${ }^{22}$ will also lead to a relative increase in dissolved $\mathrm{N}$ and $\mathrm{P}$, which are more readily available to biota and therefore likely to have a greater impact on soil biological processes than particulate or organic forms. On the other hand, the $\mathrm{C}: \mathrm{N}$ ratio in topsoils is remarkably constant, within a given ecological context. Burial and preservation of deposited $\mathrm{C}$ will therefore also lead to the stabilization of organic $\mathrm{N}$; indeed paleosol investigations report C:N ratios similar to those found in present day soils ${ }^{23}$. Data from the Chinese loess suggest that buried soil $\mathrm{P}$ contents also remain relatively stable over long ( $>10 \mathrm{kyr}$ ) periods ${ }^{24}$. This suggests that, as for $\mathrm{C}$, the stability of $\mathrm{N}$ and $\mathrm{P}$ in depositional environments may be high and may be primarily determined by the rate of $\mathrm{C}$ mineralization. At eroding sites, dynamic replacement will also lead to the stabilization of $\mathrm{N}$. However, $\mathrm{N}$ may also control C cycling: in some environments, biomass production and hence dynamic replacement may be directly limited by $\mathrm{N}$ availability $^{25}$ 
$\mathrm{C}: \mathrm{P}$ ratios in SOM show a larger variation than $\mathrm{C}: \mathrm{N}$ ratios. Furthermore, a significant part of the P reservoir in soils is stored in inorganic form. Thus, the erosional effects on $\mathrm{P}$ cycling will be less tightly coupled to $\mathrm{C}$ cycling than $\mathrm{N}$ cycling. Given that P is strongly bound to the mineral and organic soil fractions we may, as a first approximation, assume that the evolution of $\mathrm{P}$ inventories in soils will be directly proportional to the amount of soil that is either mobilized or deposited. Over time significant changes will occur. Erosion is an important mechanism for the decline in soil P content over longer time periods ${ }^{26}$ : this is not only due to the physical removal of $\mathrm{P}$ and the exposure of subsoil with lower $\mathrm{P}$ contents, but also the interaction between erosion rates and chemical weathering (see above). Over longer time periods, as P contents are reduced by erosion, the $\mathrm{P}$ in the soil profile changes from a mix of mineral, occluded, nonoccluded and organic forms to a point where soil $\mathrm{P}$ is dominated by organic and occluded forms ${ }^{26}$. In depositional sites, sediment can be an important source of P. For instance, evidence from Hawaii shows that P limitation of forest growth on old soils is alleviated to some extent by dust deposition ${ }^{27}$. At sites where erosion dominates and inputs of $\mathrm{N}$ and $\mathrm{P}$ are low, primary production declines exponentially as erosion increases ${ }^{28}$, thereby reducing the potential for dynamic SOC replacement. The reduction in primary productivity is not only due to the removal of nutrients, but also to the degradation of soil structure and, critically, reduced availability of water as soil thickness declines.

More subtle interactions may occur as well. Evidence suggests that enrichment ratios for $\mathrm{C}, \mathrm{N}$ and $\mathrm{P}$ during sediment mobilization and deposition during water erosion are not the same ${ }^{29}$. Consequently, it is likely that the relative abundance of $\mathrm{C}, \mathrm{N}$ and $\mathrm{P}$ in soils will change depending upon the relative selectivity of 
mobilization and deposition processes: enrichment associated with water and wind erosion is likely to be greater than for tillage erosion. Second, the loss of C, $\mathrm{N}$ and $\mathrm{P}$ from mobilization sites might set in motion a degenerative feedback, whereby associated declines in plant productivity further increase erosion vulnerability and hence nutrient loss. Indeed it is well established that the soil's resistance to erosion is closely linked to the stabilizing influence of organic matter ${ }^{30}$ and vegetation cover ${ }^{31}$. Conversely at deposition sites, nutrient and $\mathrm{C}$ contents may rise leading to greater primary productivity and a positive feedback on soil fertility, plant growth and resistance to erosion.

These changes may have significant impacts for a range of soil processes ${ }^{32,33}$. For instance, changes in the relative availability of $\mathrm{C}$ and $\mathrm{N}$ of soil organic matter is a primary regulator of microbial $\mathrm{N}$ mineralization-immobilization dynamics and hence plant $\mathrm{N}$ supply ${ }^{34,35}$. Changes in the $\mathrm{N}: \mathrm{P}$ ratio of soil organic matter are also known to have significant consequences for ecosystem processes of decomposition, nutrient cycling and plant production ${ }^{36,37}$. These feedbacks are likely to be of greatest significance in nutrient poor environments, such as on the nutrient poor soils of Africa and Australia where soil erosion associated with reduced vegetation cover and loss of soil $\mathrm{C}$ can trigger catastrophic shifts to a severely degraded state ${ }^{15}$. The acceleration of erosion by these mechanisms may precipitate land-use change ${ }^{38}$, which itself changes the rate of biogeochemical cycles, thereby influencing atmospheric composition and climate change ${ }^{39}$, and further disrupting $\mathrm{C}, \mathrm{N}$ and $\mathrm{P}$ cycling.

Our analysis shows that agricultural landscapes are far from static: the accelerated rates of erosion currently experienced are causing major 
modifications to the terrestrial $\mathrm{C}, \mathrm{N}$ and $\mathrm{P}$ cycles which are at present poorly understood. This has two major implications: in order to further our understanding we need to consider soils as mobile systems in order to make accurate predictions about the consequences of global change for terrestrial biogeochemical cycles and climate feedbacks. Second, the imbalance between $\mathrm{C}$ and nutrient fluxes due to erosion and $\mathrm{C}, \mathrm{N}$ and $\mathrm{P}$ inputs in many parts of the world is clearly a threat to the sustainability of food production.

\section{Corresponding author}

Correspondence should be directed to JQ

\section{Acknowledgements}

$\mathrm{KvO}$ is an FNRS funded Research Associate

\section{Contributions}

JQ led the writing of the paper $\mathrm{KvO}$ conducted the model simulations and contributed to the writing together with GG and RB .

\section{References}

1 Davidson, E.A. \& Janssens, I.A. Temperature sensitivity of soil carbon decomposition and feedbacks to climate change. Nature, 165-173. (2006).

2 Heimann, M. \& Reichstein, M. Terrestrial ecosystem carbon dynamics and climate feedbacks. Nature 451, 289-292. (2008). 
Stallard, R.F. Terrestrial sedimentation and the carbon cycling: coupling weathering and erosion to carbon burial. Glob. Biogeochem. Cycle 12, 231257 (1998).

4 Batjes, N.H., 2005. ISRIC-WISE global data set of derived soil properties on a 0.5 by 0.5 degree grid (Version 3.0). (Report 2005/08 (with data set), ISRIC-World Soil Information, Wageningen, 2005).

5 FAO, FAOSTAT, Available at faostat.fao.org.

6 Smil, V. Agriculture's Largest Harvest. BioScience 49, 299-308 (1999).

7 Seitzinger, S.P., Harrison, J.A., Dumont, E., Beusen, A.H.W., \& Bouwman, A.F. Sources and delivery of carbon, nitrogen, and phosphorus to the coastal zone: An overview of Global Nutrient Export from Watersheds (NEWS) models and their application. Glob. Biogeochem. Cycles 19 (2005).

8 Beusen, A.H.W., Dekkers, A.L.M., Bouwman, A.F., Ludwig, W., \& Harrison, J. Estimation of global river transport of sediments and associated particulate C, N, and P. Glob. Biogeochem. Cycles 19 (2005).

9 Smil, V. Phosphorus: Global Transfers in Encyclopedia of Global Environmental Change: Volume 3, Causes and consequences of global environmental change, edited by I. Douglas (John Wiley \& Sons, Chichester, 2002), pp. 536-542. Lal, R. Soil erosion and the global carbon budget. Environ. Int. 29, 437 (2003).

11 Van Oost, K. et al. The Impact of Agricultural Soil Erosion on the Global Carbon Cycle. Science 318 626-629 (2007). 
Van Hemelryck, H., P. Fiener, K. Van Oost, \& Govers, G. The effect of soil redistribution on soil organic carbon: an experimental study. Biogeosciences Discuss. 6, 5031-5071 (2009).

Cole, J. et al. Plumbing the global carbon cycle: integrating inland waters into the terrestrial carbon budget. Ecosystems 10, 172-185 (2007). vandeKoppel, J., Rietkerk, M., \& Weissing, F.J. Catastrophic vegetation shifts and soil degradation in terrestrial grazing systems. Trends Ecol. Evol. 12, 352-356 (1997).

Berhe, A., Harte, J., Harden, J., \& Torn, M. The significance of the erosioninduced terrestrial carbon sink. BioScience 57, 337-346 (2007).

Riebe, C., Kirchner, J., Granger, D., \& Finkel, R. Strong tectonic and weak climatic control of long-term chemical weathering rates. Geology 29, 511514 (2001). 

Indicators for Policy Analyses. Proceedings of an OECD expert meeting, Ottawa, Canada, 2002 (unpublished). Jacinthe, P.A., Lal, R., \& Kimble, J.M. Carbon dioxide evolution in runoff from simulated rainfall on long-term no-till and plowed soils in southwestern Ohio. Soil Tillage Res. 66, 23-33 (2002).

Inoue, Y., Baasansuren, J. Watanabe, M., Kamei, H., \& Lowe, D.J., Interpretation of pre-AD 472 Roman soils from physicochemical and mineralogical properties of buried tephric paleosols at Somma Vesuviana ruin, southwest Italy. Geoderma 152, 243-251 (2009).

Rao, W., Chen, J., Luo, T., \& Liu, L. Phosphorus geochemistry in the Luochuan loess section, North China and its paleoclimatic implications. Quat. Int.144, 72-83 (2006). van Groenigen, K.-J. et al. Element interactions limit soil carbon storage. Proc. Natl Acad. Sci. USA 103, 6571-6574 (2006). Filippelli, G.M. The Global Phosphorus Cycle: Past, Present, and Future. Elements 4, 89-95 (2008).

Chadwick, O., Derry, L., Vitousek, P., Huebert, B., \& Hedin, L. Changing sources of nutrients during four million years of ecosystem development. Nature 397, 491-497 (1999).

Stocking, M.A. Tropical Soils and Food Security: The Next 50 Years. Science 302 1356-1359 (2003). 
Sharpley, A.N. The selective erosion of plant nutrients in runoff. Soil Sci. Soc. Am. J. 49, 1527-1534 (1985).

Tisdall, J. \& Oades, J. Organic matter and water-stable aggregates in soils. J. Soil Sci. 33, 141-163 (1982).

Elwell, H. \& Stocking, M. Vegetal cover to estimate soil erosion hazard in Rhodesia. Geoderma (Netherlands) (1976).

Woodward, F., Bardgett, R., Raven, J., \& Hetherington, A. Biological Approaches to Global Environment Change Mitigation and Remediation. Current Biology 19, 615-623 (2009).

Reay, D., Dentener, F., Smith, P., Grace, J., \& Feely, R. Global nitrogen deposition and carbon sinks. Nature Geoscience 1, 430-437 (2008).

Kaye, J.P. \& Hart., S.C. Competition for nitrogen between plants and soil microorganisms. Trends Ecol. Evol. 12, 139-143. (1997).

Bardgett, R.D. The Biology of Soil: A Community and Ecosytems Approach, 1st ed. (Oxford University Press, Oxford, UK., 2005).

Wardle, D.A., L. R. Walker, \& Bardgett, R. D. Ecosystem properties and forest decline in contrasting long-term chronosequences. Science 305, 509-513 (2004).

Wardle, D., Bardgett, R., Walker, L., \& Bonner, K., Among- and withinspecies variation in plant litter decomposition in contrasting long-term chronosequences. Funct. Ecology 23, 442-453 (2009).

Bakker, M.M. et al. Soil erosion as a driver of land-use change. Agric. Ecosyst. Environ. 105, 467-481 (2005). 
Future Climates. Science 310, 1674-1678 (2005). 


\section{Figure captions}

Figure 1. Global distribution of sediment fluxes (shaded map), derived using methods described in S2, and continental fluxes of $\mathrm{N}$ and $\mathrm{P}$ by water and tillage erosion compared to fertilizer use ${ }^{6}$ (bars). Inset compares global fluxes of $\mathrm{N}$ and $\mathrm{P}\left(\mathrm{Tg} \mathrm{yr}^{-1}\right)$ due to erosion, fertilizer input and crop uptake.

Figure 2: Interplay between soil erosion, land use/soil management and C cycling at sites of erosion. The shaded area reflects possible combinations of $\mathrm{C}$ residence time (1/decomposition rate) and erosion rates as a function of land use/management, while the data $\left(\mathrm{g} \mathrm{C} \mathrm{m}^{-2} \mathrm{yr}^{-1}\right)$ and size of the circles represents the maximum size of the $C$ sink (positive, green) or source (negative, red) (see S2). For croplands, the data represent high-input systems (HI, low sensitivity to

yield decline, $4 \%$ per $0.1 \mathrm{~m}$ erosion) and low-input systems (LI, high sensitivity to yield decline, $15 \%$ per $0.1 \mathrm{~m}$ erosion). 


\section{The impact of agricultural soil erosion on biogeochemical}

\section{cycling}

John Quinton, Lancaster University, Gerard Govers, KU Leuven and Kristof Van Oost

UC Louvain, Richard Bardgett, Lancaster University

\section{Introductory paragraph}

It is widely recognized that soils play a key role in controlling the storage, transformation and flux of nutrients and carbon $(\mathrm{C})$ through the lithosphere and biosphere. Despite this, our understanding of the role that soils play in biogeochemical cycles does not conventionally take into account erosion, lateral movement and soil mixing. Here, we synthesize data on the global fluxes of soil C, nitrogen $(\mathrm{N})$ and phosphorus $(\mathrm{P})$ moving over agricultural landscapes as a result of erosion processes. We demonstrate how the mobilization and deposition of soil can have significant impacts on carbon and nutrient cycling causing lateral fluxes of $\mathrm{N}$ and $\mathrm{P}$ similar in magnitude to those induced by fertilizer application and crop removal. The translocation and burial of $\mathrm{C}$ reduces decomposition and may lead to a potential $\mathrm{C}$ sink. Cycling of $\mathrm{C}, \mathrm{N}$ and $\mathrm{P}$ and phosphorus are strongly interrelated, and lateral fluxes of soil, $\mathrm{C}$ and associated nutrients have significant consequences for primary productivity, which in turn influences the replacement

of lost C. Our analysis demonstrates why soils must be viewed as dynamic systems in time and space if we are to understand their role in major biogeochemical cycles. 


\section{Introduction}

Soils are the major terrestrial reservoir of organic carbon (C) and nutrients such as nitrogen (N) and phosphorus (P), and the potential impact of soil processes on the biogeochemical cycling of these elements remains one of the great uncertainties in our knowledge of global climate change ${ }^{1,2}$. Beginning with the pioneering work of Stallard ${ }^{3}$, scientists have become increasingly aware that lateral fluxes induced by soil erosion are of key importance in the global C cycle. Work on the relationship between erosion and nutrients has hitherto focused mainly on potential losses of nutrients due to erosion and the effect on primary productivity; potential effects of erosion on global nutrient cycling and their interrelationship with the carbon cycle have not yet been studied in detail. In this progress article we estimate the impact of soil erosion on the cycling of $\mathrm{C}, \mathrm{N}$ and $\mathrm{P}$ using global datasets and identify mechanisms through which erosion and $\mathrm{C}, \mathrm{N}$ and $\mathrm{P}$ cycling may interact.

\section{Mobilizing elements}

Several estimates of global soil and C erosion rates associated with agriculture have been made in recent years. From a critical analysis of these estimates we calculate the sediment by water erosion flux to be about $28 \mathrm{Pg} \mathrm{yr}^{-1}$, and that an additional approximately $5 \mathrm{Pg} \mathrm{yr}^{-1}$ and $2 \mathrm{Pg} \mathrm{yr}^{-1}$ of sediment are mobilized by tillage and wind erosion, respectively, leading to a total sediment flux of about 35

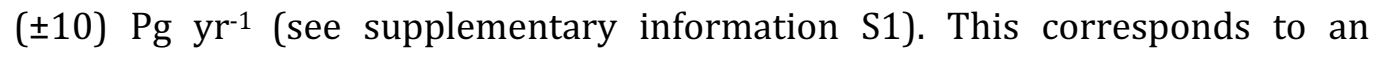
agricultural C erosion flux of $0.5( \pm 0.15) \mathrm{Pg} \mathrm{C} \mathrm{yr}^{-1}$ and an estimate of $0.08( \pm 0.02)$ Pg for C delivery to river systems by water erosion. 
To estimate the flux of $\mathrm{N}$ associated with erosion processes, we combine spatial estimates of soil erosion with global soil $\mathrm{N}$ data ${ }^{4}$ (see supplementary information S1). We estimate the amount of $\mathrm{N}$ moved by erosion to be of the order of 23-42 $\mathrm{Tg} \mathrm{N} \mathrm{yr}^{-1}$. Lateral fluxes of $\mathrm{N}$ due to erosion are of the same order of magnitude as

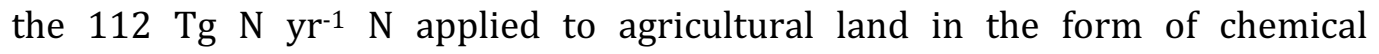
fertilizers ${ }^{5}$, the $75 \mathrm{Tg} \mathrm{yr}^{-1} \mathrm{~N}$ removed in harvested crops ${ }^{6}$ and the estimated riverine fluxes of particulate $\mathrm{N}$ of between 23 and $30 \mathrm{Tg} \mathrm{N} \mathrm{yr}^{-1}$ 7,8. We estimate soil erosion-driven terrestrial fluxes of organic and inorganic $\mathrm{P}$ to be $2.1-3.9 \mathrm{Tg}$

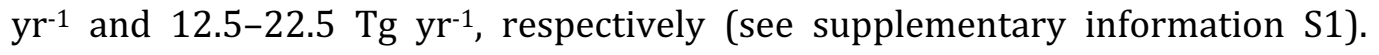
However, due to the limited availability of global soil P data these estimates are uncertain. Global mean P fluxes are considerably lower than the $40 \mathrm{Pg}$ of global soil P stocks ${ }^{9}$, but of similar magnitude to crop uptake ${ }^{6}\left(14 \mathrm{Tg} \mathrm{yr}^{-1}\right)$ and fertilizer $\mathrm{P}$ added to agricultural land (ca. $18 \mathrm{Tg} \mathrm{yr}^{-1}$ ). However, in some parts of the world global fluxes of $\mathrm{P}$ do exceed $\mathrm{P}$ additions (Figure 1), adding further downward pressures on soil fertility, and food production.

\section{Eroding the carbon cycle}

Soil erosion encompasses soil mobilization (detachment), transport and deposition phases. Understanding erosional effects on biogeochemical cycles requires consideration of all three components. When soil material is mobilized, soil structure is at least partially disrupted. Laboratory experiments indicate that a significant increase in the rate of soil organic C (SOC) mineralization is possible

during or shortly after sediment mobilization, potentially leading to the loss of $>20 \%$ of the total SOC as $\mathrm{CO}_{2}, 10$. When considering the potential role of the transport phase, a distinction should be made between SOC deposited in a local 
depositional store after being transported over a relatively small distance $(<5 \mathrm{~m})$ by water or tillage with a short time span ( $<1$ day), and the fate of SOC that is delivered to the river ecosystem. Field observations suggest the additional SOC mineralization that occurs during transport over land is relatively unimportant: erosion-deposition simulations based on ${ }^{137} \mathrm{Cs}$ inventories show that the $\mathrm{C}$ inventory found at depositional sites is inconsistent with significant mineralization during the transport phase ${ }^{11}$. Recent observations under field conditions suggest that SOC losses from soil that is re-deposited after a short transport phase are relatively low $(<2.5 \%$ of eroded SOC), and therefore not very significant for the global C budget ${ }^{12}$. On the other hand, SOC that is delivered to the river system may be to a large extent mineralized within the river system ${ }^{13}$.

Understanding erosional effects on biogeochemical cycling also requires consideration of longer-term effects. Recent work on the impact of soil erosion on the $\mathrm{C}$ cycle has implicated eroded sites in both increased emissions and sequestration of C. While soil structure disruption during erosion may immediately lead to $\mathrm{CO}_{2}$ emission, enhanced emissions over longer time spans are associated with a reduced capacity of eroded soils to support plant growth ${ }^{14}$ resulting in lower $\mathrm{C}$ inputs through plant and root matter ${ }^{15}$. Erosion will also lead to local mixing of C-depleted subsoil into the plough layer. This offers potential for $\mathrm{C}$ sequestration through so-called dynamic replacement ${ }^{16}$ as: (i) the mean $\mathrm{C}$ concentration in the soil will be reduced and will therefore be lower than the equilibrium $\mathrm{C}$ concentration; and (ii) as relatively fresh mineral surfaces will be exposed on which soil organic matter may be more easily bound. If erosion is controlled there is potential for additional $\mathrm{C}$ sequestration at eroded sites as SOM contents may increase. The promotion of $\mathrm{C}$ sequestration by erosion relies 
on a reduced rate of SOC decomposition because sediment is buried in depositional environments. Although the mechanisms which contribute to the reduction of decomposition at depth ${ }^{17}$ have only recently received attention ${ }^{18}$, the burial of pedogenic $C$ at sites of deposition has been shown repeatedly to stabilize soil $\mathrm{C}$ at timescales of several decades, leading to reduced atmospheric release of $\mathrm{C}^{11}$. In addition to this passive mechanism of SOC mineralization suppression, active sequestration can also take place in depositional environments with a higher net primary production than the source areas. For example, the influx of low $\mathrm{C}$ sediment into wetlands and lowland valley bottoms may stimulate net $\mathrm{C}$ sequestration by diluting the concentration of soil $\mathrm{C}^{3}$. Overall, the extent to which mobilization and deposition lead to an overall sink of atmospheric $\mathrm{CO}_{2}$ is critically dependent on how much of the depositional accumulation is replaced by newly produced plant-derived soil C at eroding $\operatorname{sites}^{16}$ (figure 2).

The removal of soil also brings the subsoil and parent material closer to the soil surface. For silicate-rich parent material there is increasing empirical and theoretical evidence for a link between erosion and rates of chemical weathering under steady state conditions ${ }^{19,20}$. Since the weathering of silicate minerals consumes $\mathrm{CO}_{2}$, it seems likely that there may also be a link between erosioninduced weathering and the consumption of $\mathrm{CO}_{2}$, although the flux is likely to be small,. In contrast, where parent materials are calcareous, accelerated weathering may result in $\mathrm{CO}_{2}$ release to the atmosphere. For example, in the Canadian prairies it has been estimated that that $10 \%$ of the carbonates acidified may be released as $\mathrm{CO}_{2}$, producing an estimated $\mathrm{C}$ loss of 0.12 to $1.2 \mathrm{Mg} \mathrm{ha}^{-1} \mathrm{yr}^{-1}$ 21. 


\section{Impact on nutrient cycles}

Work on the effects of erosion on $\mathrm{N}$ and $\mathrm{P}$ cycling has hitherto concentrated on the assessment of nutrient mobilization and delivery to aquatic ecosystems. Very little work has been carried out on how $\mathrm{N}$ and $\mathrm{P}$ cycling within terrestrial environments are affected by erosion. Here we propose a conceptualization of how the effects of erosion on $\mathrm{C}, \mathrm{N}$ and $\mathrm{P}$ cycling may be interrelated. Because large amounts of $\mathrm{N}$ and $\mathrm{P}$ are retained within the soil organic matter (SOM) fraction, enhanced mineralization of soil $\mathrm{C}$ due to soil mobilization ${ }^{22}$ will also lead to a relative increase in dissolved $\mathrm{N}$ and $\mathrm{P}$, which are more readily available to biota and therefore likely to have a greater impact on soil biological processes than particulate or organic forms. On the other hand, the C:N ratio in topsoils is remarkably constant, within a given ecological context. Burial and preservation of deposited $\mathrm{C}$ will therefore also lead to the stabilization of organic $\mathrm{N}$; indeed paleosol investigations report C:N ratios similar to those found in present day soils ${ }^{23}$. Data from the Chinese loess suggest that buried soil $\mathrm{P}$ contents also remain relatively stable over long ( $>10 \mathrm{kyr})$ periods ${ }^{24}$. This suggests that, as for $\mathrm{C}$, the stability of $\mathrm{N}$ and $\mathrm{P}$ in depositional environments may be high and may be primarily determined by the rate of $\mathrm{C}$ mineralization. At eroding sites, dynamic replacement will also lead to the stabilization of $\mathrm{N}$. However, $\mathrm{N}$ may also control $\mathrm{C}$ cycling: in some environments, biomass production and hence dynamic replacement may be directly limited by $\mathrm{N}$ availability $^{25}$ 
$\mathrm{C}: \mathrm{P}$ ratios in SOM show a larger variation than $\mathrm{C}: \mathrm{N}$ ratios. Furthermore, a significant part of the P reservoir in soils is stored in inorganic form. Thus, the erosional effects on $\mathrm{P}$ cycling will be less tightly coupled to $\mathrm{C}$ cycling than $\mathrm{N}$ cycling. Given that P is strongly bound to the mineral and organic soil fractions we may, as a first approximation, assume that the evolution of $\mathrm{P}$ inventories in soils will be directly proportional to the amount of soil that is either mobilized or deposited. Over time significant changes will occur. Erosion is an important mechanism for the decline in soil P content over longer time periods ${ }^{26}$ : this is not only due to the physical removal of $\mathrm{P}$ and the exposure of subsoil with lower $\mathrm{P}$ contents, but also the interaction between erosion rates and chemical weathering (see above). Over longer time periods, as P contents are reduced by erosion, the $\mathrm{P}$ in the soil profile changes from a mix of mineral, occluded, nonoccluded and organic forms to a point where soil $\mathrm{P}$ is dominated by organic and occluded forms ${ }^{26}$. In depositional sites, sediment can be an important source of P. For instance, evidence from Hawaii shows that P limitation of forest growth on old soils is alleviated to some extent by dust deposition ${ }^{27}$. At sites where erosion dominates and inputs of $\mathrm{N}$ and $\mathrm{P}$ are low, primary production declines exponentially as erosion increases ${ }^{28}$, thereby reducing the potential for dynamic SOC replacement. The reduction in primary productivity is not only due to the removal of nutrients, but also to the degradation of soil structure and, critically, reduced availability of water as soil thickness declines.

More subtle interactions may occur as well. Evidence suggests that enrichment ratios for $\mathrm{C}, \mathrm{N}$ and $\mathrm{P}$ during sediment mobilization and deposition during water erosion are not the same ${ }^{29}$. Consequently, it is likely that the relative abundance of $\mathrm{C}, \mathrm{N}$ and $\mathrm{P}$ in soils will change depending upon the relative selectivity of 
mobilization and deposition processes: enrichment associated with water and wind erosion is likely to be greater than for tillage erosion. Second, the loss of C, $\mathrm{N}$ and $\mathrm{P}$ from mobilization sites might set in motion a degenerative feedback, whereby associated declines in plant productivity further increase erosion vulnerability and hence nutrient loss. Indeed it is well established that the soil's resistance to erosion is closely linked to the stabilizing influence of organic matter ${ }^{30}$ and vegetation cover ${ }^{31}$. Conversely at deposition sites, nutrient and $\mathrm{C}$ contents may rise leading to greater primary productivity and a positive feedback on soil fertility, plant growth and resistance to erosion.

These changes may have significant impacts for a range of soil processes ${ }^{32,33}$. For instance, changes in the relative availability of $\mathrm{C}$ and $\mathrm{N}$ of soil organic matter is a primary regulator of microbial $\mathrm{N}$ mineralization-immobilization dynamics and hence plant $\mathrm{N}$ supply ${ }^{34,35}$. Changes in the $\mathrm{N}: \mathrm{P}$ ratio of soil organic matter are also known to have significant consequences for ecosystem processes of decomposition, nutrient cycling and plant production ${ }^{36,37}$. These feedbacks are likely to be of greatest significance in nutrient poor environments, such as on the nutrient poor soils of Africa and Australia where soil erosion associated with reduced vegetation cover and loss of soil $\mathrm{C}$ can trigger catastrophic shifts to a severely degraded state ${ }^{15}$. The acceleration of erosion by these mechanisms may precipitate land-use change ${ }^{38}$, which itself changes the rate of biogeochemical cycles, thereby influencing atmospheric composition and climate change ${ }^{39}$, and further disrupting $\mathrm{C}, \mathrm{N}$ and $\mathrm{P}$ cycling.

Our analysis shows that agricultural landscapes are far from static: the accelerated rates of erosion currently experienced are causing major 
modifications to the terrestrial $\mathrm{C}, \mathrm{N}$ and $\mathrm{P}$ cycles which are at present poorly understood. This has two major implications: in order to further our understanding we need to consider soils as mobile systems in order to make accurate predictions about the consequences of global change for terrestrial biogeochemical cycles and climate feedbacks. Second, the imbalance between $\mathrm{C}$ and nutrient fluxes due to erosion and $\mathrm{C}, \mathrm{N}$ and $\mathrm{P}$ inputs in many parts of the world is clearly a threat to the sustainability of food production.

\section{Corresponding author}

Correspondence should be directed to JQ

\section{Acknowledgements}

$\mathrm{KvO}$ is an FNRS funded Research Associate

\section{Contributions}

JQ led the writing of the paper KvO conducted the model simulations and contributed to the writing together with GG and RB .

\section{References}

1 Davidson, E.A. \& Janssens, I.A. Temperature sensitivity of soil carbon decomposition and feedbacks to climate change. Nature, 165-173. (2006).

2 Heimann, M. \& Reichstein, M. Terrestrial ecosystem carbon dynamics and climate feedbacks. Nature 451, 289-292. (2008). 
Stallard, R.F. Terrestrial sedimentation and the carbon cycling: coupling weathering and erosion to carbon burial. Glob. Biogeochem. Cycle 12, 231257 (1998).

4 Batjes, N.H., 2005. ISRIC-WISE global data set of derived soil properties on a 0.5 by 0.5 degree grid (Version 3.0). (Report 2005/08 (with data set), ISRIC-World Soil Information, Wageningen, 2005).

5 FAO, FAOSTAT, Available at faostat.fao.org.

6 Smil, V. Agriculture's Largest Harvest. BioScience 49, 299-308 (1999).

7 Seitzinger, S.P., Harrison, J.A., Dumont, E., Beusen, A.H.W., \& Bouwman, A.F. Sources and delivery of carbon, nitrogen, and phosphorus to the coastal zone: An overview of Global Nutrient Export from Watersheds (NEWS) models and their application. Glob. Biogeochem. Cycles 19 (2005).

8 Beusen, A.H.W., Dekkers, A.L.M., Bouwman, A.F., Ludwig, W., \& Harrison, J. Estimation of global river transport of sediments and associated particulate C, N, and P. Glob. Biogeochem. Cycles 19 (2005).

9 Smil, V. Phosphorus: Global Transfers in Encyclopedia of Global Environmental Change: Volume 3, Causes and consequences of global environmental change, edited by I. Douglas (John Wiley \& Sons, Chichester, 2002), pp. 536-542. (2003). Van Oost, K. et al. The Impact of Agricultural Soil Erosion on the Global Carbon Cycle. Science 318 626-629 (2007). 
Van Hemelryck, H., P. Fiener, K. Van Oost, \& Govers, G. The effect of soil redistribution on soil organic carbon: an experimental study. Biogeosciences Discuss. 6, 5031-5071 (2009).

Cole, J. et al. Plumbing the global carbon cycle: integrating inland waters into the terrestrial carbon budget. Ecosystems 10, 172-185 (2007). vandeKoppel, J., Rietkerk, M., \& Weissing, F.J. Catastrophic vegetation shifts and soil degradation in terrestrial grazing systems. Trends Ecol. Evol. 12, 352-356 (1997).

Berhe, A., Harte, J., Harden, J., \& Torn, M. The significance of the erosioninduced terrestrial carbon sink. BioScience 57, 337-346 (2007).

Harden, J.W. et al. Dynamic replacement and loss of soil carbon on eroding cropland. Glob. Biogeochem. Cycle 13, 885-901 (1999). control of landscape carbon accumulation. J. Geophys. Res. 111, G01004 (2006).

Fontaine, S. et al. Stability of organic carbon in deep soil layers controlled by fresh carbon supply. Nature 450, 277-280 (2007).

Gabet, E.J. \& Mudd, S.M. A theoretical model coupling chemical weathering rates with denudation rates. Geology 37, 151-154 (2009).

Riebe, C., Kirchner, J., Granger, D., \& Finkel, R. Strong tectonic and weak climatic control of long-term chemical weathering rates. Geology 29, 511$514(2001)$ 

Indicators for Policy Analyses. Proceedings of an OECD expert meeting, Ottawa, Canada, 2002 (unpublished). Jacinthe, P.A., Lal, R., \& Kimble, J.M. Carbon dioxide evolution in runoff from simulated rainfall on long-term no-till and plowed soils in southwestern Ohio. Soil Tillage Res. 66, 23-33 (2002). Inoue, Y., Baasansuren, J. Watanabe, M., Kamei, H., \& Lowe, D.J., Interpretation of pre-AD 472 Roman soils from physicochemical and mineralogical properties of buried tephric paleosols at Somma Vesuviana ruin, southwest Italy. Geoderma 152, 243-251 (2009).

Rao, W., Chen, J., Luo, T., \& Liu, L. Phosphorus geochemistry in the Luochuan loess section, North China and its paleoclimatic implications. Quat. Int.144, 72-83 (2006). van Groenigen, K.-J. et al. Element interactions limit soil carbon storage. Proc. Natl Acad. Sci. USA 103, 6571-6574 (2006).

Filippelli, G.M. The Global Phosphorus Cycle: Past, Present, and Future. Elements 4, 89-95 (2008).

Chadwick, O., Derry, L., Vitousek, P., Huebert, B., \& Hedin, L. Changing sources of nutrients during four million years of ecosystem development. Nature 397, 491-497 (1999).

Stocking, M.A. Tropical Soils and Food Security: The Next 50 Years. Science 302 1356-1359 (2003). 
Sharpley, A.N. The selective erosion of plant nutrients in runoff. Soil Sci. Soc. Am. J. 49, 1527-1534 (1985).

Tisdall, J. \& Oades, J. Organic matter and water-stable aggregates in soils. J. Soil Sci. 33, 141-163 (1982).

Elwell, H. \& Stocking, M. Vegetal cover to estimate soil erosion hazard in Rhodesia. Geoderma (Netherlands) (1976).

Woodward, F., Bardgett, R., Raven, J., \& Hetherington, A. Biological Approaches to Global Environment Change Mitigation and Remediation. Current Biology 19, 615-623 (2009).

Reay, D., Dentener, F., Smith, P., Grace, J., \& Feely, R. Global nitrogen deposition and carbon sinks. Nature Geoscience 1, 430-437 (2008).

Kaye, J.P. \& Hart., S.C. Competition for nitrogen between plants and soil microorganisms. Trends Ecol. Evol. 12, 139-143. (1997).

Bardgett, R.D. The Biology of Soil: A Community and Ecosytems Approach, 1st ed. (Oxford University Press, Oxford, UK., 2005).

Wardle, D.A., L. R. Walker, \& Bardgett, R. D. Ecosystem properties and forest decline in contrasting long-term chronosequences. Science 305, 509-513 (2004).

Wardle, D., Bardgett, R., Walker, L., \& Bonner, K., Among- and withinspecies variation in plant litter decomposition in contrasting long-term chronosequences. Funct. Ecology 23, 442-453 (2009).

Bakker, M.M. et al. Soil erosion as a driver of land-use change. Agric. Ecosyst. Environ. 105, 467-481 (2005). 
Future Climates. Science 310, 1674-1678 (2005). 


\section{Figure captions}

Figure 1. Global distribution of sediment fluxes (shaded map), derived using methods described in S2, and continental fluxes of $\mathrm{N}$ and $\mathrm{P}$ by water and tillage erosion compared to fertilizer use ${ }^{6}$ (bars). Inset compares global fluxes of $\mathrm{N}$ and $\mathrm{P}\left(\mathrm{Tg} \mathrm{yr}^{-1}\right)$ due to erosion, fertilizer input and crop uptake.

Figure 2: Interplay between soil erosion, land use/soil management and C cycling at sites of erosion. The shaded area reflects possible combinations of $\mathrm{C}$ residence time (1/decomposition rate) and erosion rates as a function of land use/management, while the data $\left(\mathrm{g} \mathrm{C} \mathrm{m}^{-2} \mathrm{yr}^{-1}\right)$ and size of the circles represents the maximum size of the $C$ sink (positive, green) or source (negative, red) (see S2). For croplands, the data represent high-input systems (HI, low sensitivity to

yield decline, $4 \%$ per $0.1 \mathrm{~m}$ erosion) and low-input systems (LI, high sensitivity to yield decline, $15 \%$ per $0.1 \mathrm{~m}$ erosion). 

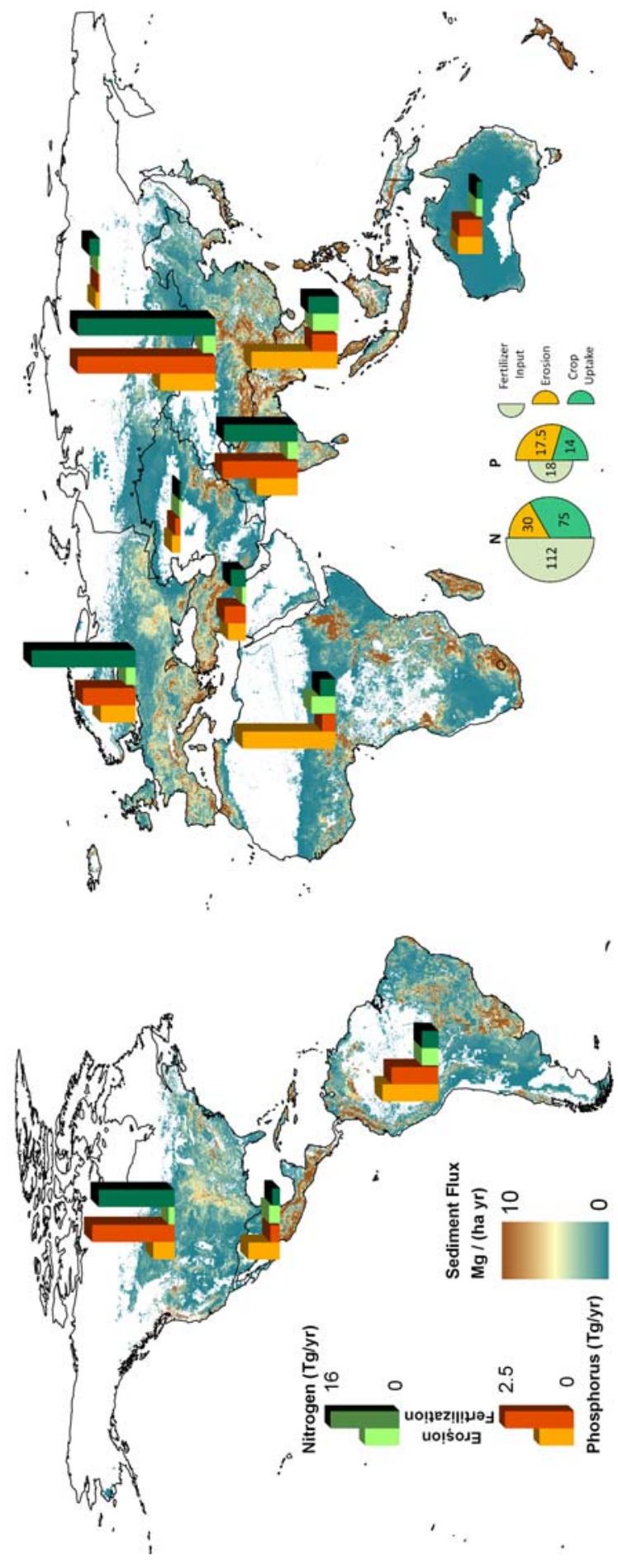


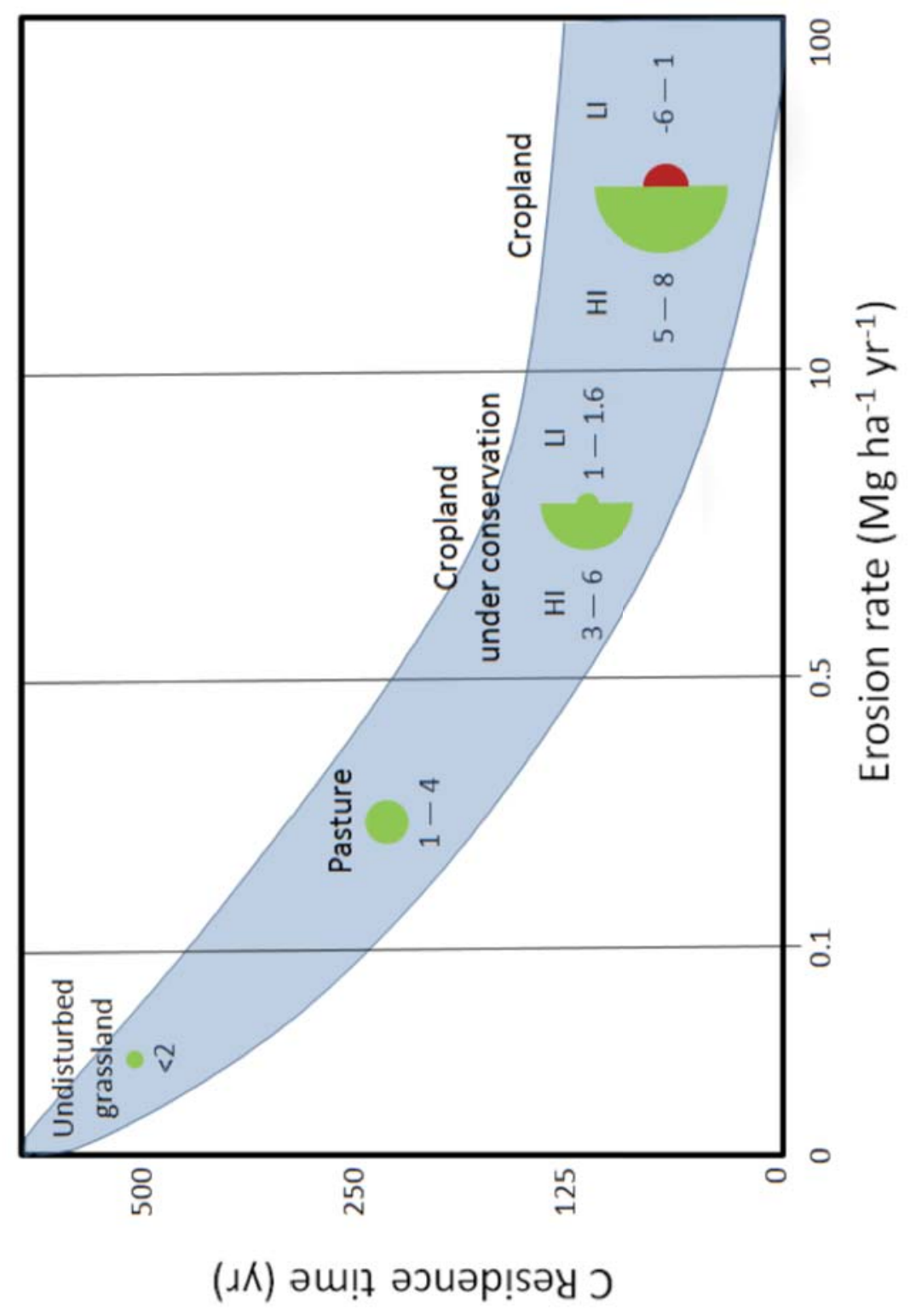



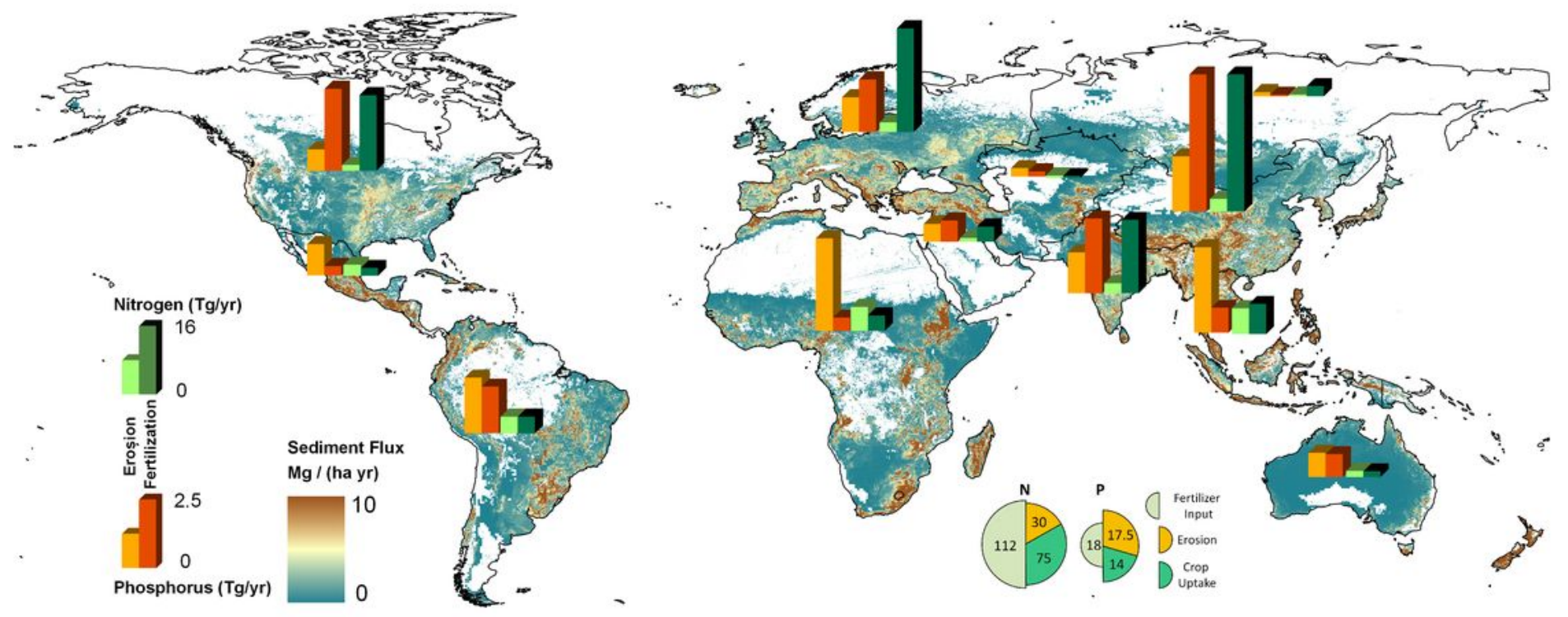


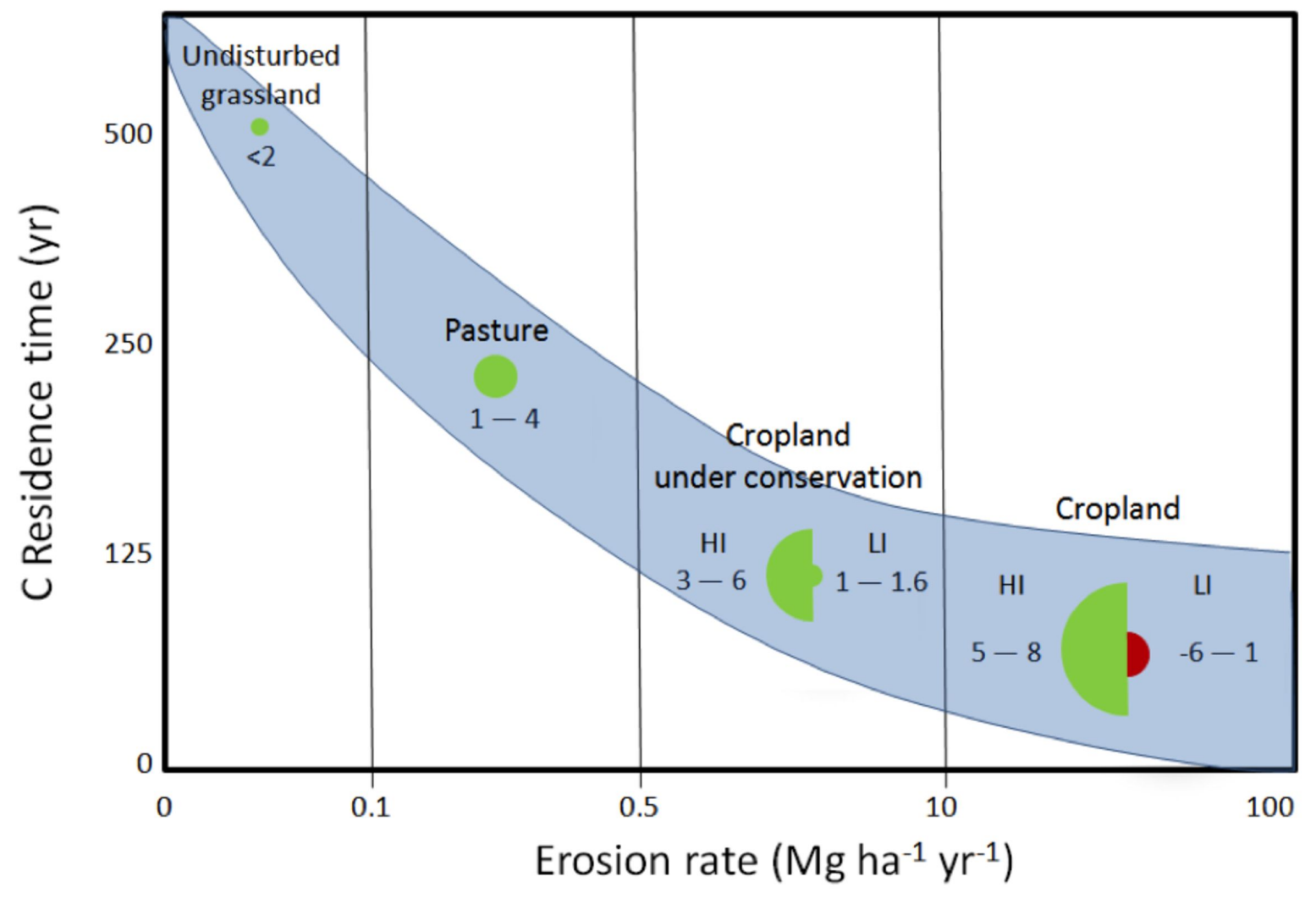

